\title{
Evaluation of factors associated with failure of tuberculosis treatment under DOTS in northern Islamic Republic of Iran
}

Kh. Ali Mohammadzadeh, ${ }^{7}$ A. Ghayoomi ${ }^{2}$ and D. Maghsoudloo

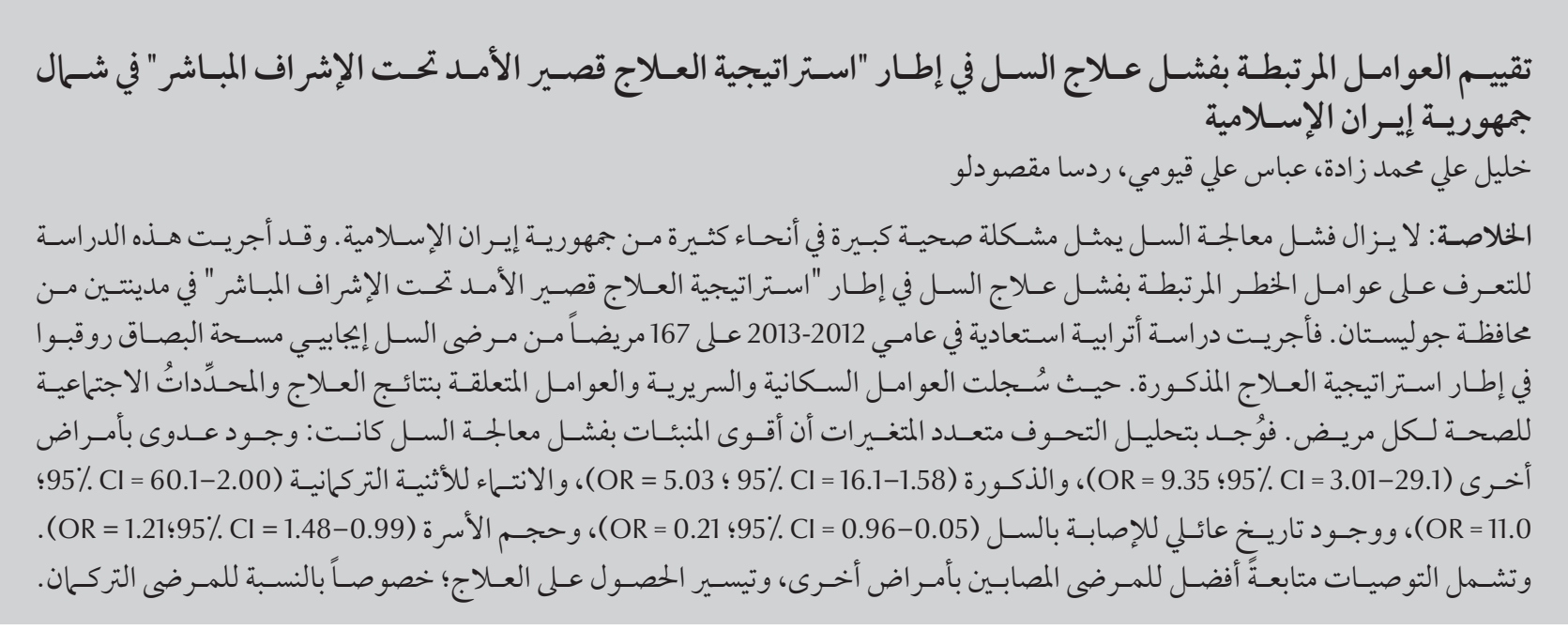

ABSTRACT Tuberculosis treatment failure remains a major health problem in many parts of the Islamic Republic of Iran. This study was conducted to identify the risk factors associated with failure of tuberculosis treatment under the DOTS strategy in two cities of Golestan province. A retrospective cohort study in 2012-2013 was conducted on 167 smearpositive tuberculosis patients monitored under DOTS. Demographic, clinical and treatment outcome factors and social determinants of health were recorded for each patient. Multivariate regression analysis found that the strongest predictors of tuberculosis treatment failure were: being infected with other diseases (OR 9.35; 95\% Cl: 3.01-29.1), male sex (OR 5.03; 95\% Cl: 1.58-16.1), Turkoman ethnicity (OR 11.0; 95\% Cl: 2.00-60.1), family history of tuberculosis (OR 0.21; 95\% Cl: 0.05-0.96) and household size (OR 1.21; 95\% Cl: 0.99-1.48). Recommendations include better follow-up for patients with other diseases and facilitating access to treatment, especially for Turkoman patients.

Évaluation des facteurs associés à l'échec du traitement antituberculeux dans le cadre du DOTS (traitement de brève durée sous surveillance directe) dans le nord de la République islamique d'Iran

RÉSUMÉ L'échec du traitement antituberculeux demeure un problème de santé majeur dans de nombreuses régions de la République islamique d'Iran. La présente étude a été réalisée dans le but d'identifier les facteurs de risque associés à l'échec du traitement antituberculeux dans le cadre de la stratégie DOTS dans deux villes de la province de Golestan. En 2012 et 2013, une étude de cohorte rétrospective a été menée auprès de 167 patients à frottis positifs qui étaient sous surveillance DOTS. Les facteurs démographiques, cliniques ainsi que ceux qui concernent les issues thérapeutiques et les déterminants sociaux de la santé ont été enregistrés pour chaque patient. L'analyse de régression multivariée a révélé que les prédicteurs de l'échec du traitement antituberculeux les plus importants étaient les suivants : le fait d'être porteur d'infections concomitantes (OR 9,35; IC à $95 \%$ : 3,01 - 29,1), être de sexe masculin (OR 5,03; IC à $95 \%$ : 1,58 - 16,1), d'appartenir à l'ethnie turkmène (OR 11,0 ; IC à $95 \%: 2,00$ - 60,1), d'avoir des antécédents familiaux de tuberculose (OR 0,21; IC à $95 \%: 0,05-0,96)$ et la taille du ménage (OR 1,21; IC à $95 \%$ : 0,99 - 1,48). Les recommandations comprennent l'amélioration du suivi des patients atteints d'autres maladies ainsi que le fait de faciliter de l'accès au traitement, en particulier pour les patients turkmènes. 


\section{Introduction}

One of the main tasks of all health care systems is the management of diseases (1). The World Health Organization $(\mathrm{WHO})$ has recommended approaches toward communicable diseases which are based on the regional and geographic characteristics of each country (2). Among these diseases, tuberculosis continues to be a major public health problem across the world with an estimated 8.7 million incident cases globally in 2011, equivalent to 125 cases per 100000 people (3). In the Islamic Republic of Iran, the incidence and prevalence of tuberculosis were estimated at 21 and 31 in 100000 respectively, and the reported incidence of sputum smear-positive tuberculosis was 7.38 per 100000 people in 2011 (4).

The WHO's Stop TB strategy aims to dramatically reduce the global burden of tuberculosis. At the heart of the strategy lies the DOTS (directly observed treatment, short-course) programme (5). Treatment failure is a serious problem for tuberculosis control programmes in many countries throughout the world (6). Understanding the specific reasons for unsuccessful outcomes is important in order to improve treatment systems (7). DOTS has been practised for more than 20 years, yet many tuberculosis patients continue to go undiagnosed and fail to receive proper treatment in many parts of the Islamic Republic of Iran (8). Tuberculosis is a disease that can be easily and effectively controlled if it is detected at an early stage and the right course of treatment is adopted (9).

The results of a study of risk factors of tuberculosis treatment failure in the south-east of the Islamic Republic of Iran showed that family history of tuberculosis, weight loss during treatment, smoking and drug addiction were risk factors for treatment failure in the national tuberculosis control programme (10). Golestan province has a very high incidence of tuberculosis (11); in 2011 the estimated incidence of tuberculosis cases was 51 per 100000 and of sputum-positive cases was 24.5 per 100000 (12). Therefore, identification of the factors contributing to treatment failure in this region is extremely important; familiarity with these factors can lead to an improvement in treatment strategies, with the aim of reducing the incidence of treatment failure in those afflicted with this disease. Within Golestan province, an especially high number of tuberculosis cases have been recorded in the city of Aqqala (103.8 per 100000 for all incident tuberculosis cases and 23.8 per 100000 for sputum-positive incident cases in 2011) as well as in the city of Gorgan (51.1 per 100000 for incident cases and 45.8 per 100000 for sputum-positive cases) (12). A study was therefore conducted during the period 2012-13 with the aim of determining the factors associated with failure of treatment under the DOTS strategy in these 2 cities in northern Islamic Republic of Iran.

\section{Methods}

\section{Study design and sampling}

This was a retrospective cohort study. The study population comprised all newly diagnosed smear-positive tuberculosis cases in Gorgan and Aqqala cities during the year 2012-13. The criteria for entry to the study were being a new smear-positive TB patient, being treated in the DOTS programme and having a tuberculosis number assigned by the health department of one of those cities. The criteria for exiting the study were death, an erroneous detection of tuberculosis and the emigration of a patient from the area. Of the 178 patients with new smear-positive tuberculosis during 2012-13 who entered the study and for whom a checklist was completed, 6 patients died, 3 of them moved, and 2 individuals were erroneously detected as smear-positive. In the end, data from a total of 167 patients were analysed.

As per national guidelines, a smearpositive tuberculosis patient was one who had at least 2 positive sputum acidfast bacilli (AFB) smears, or one who had only 1 positive sputum AFB smear but whose lung X-ray scan showed pulmonary tuberculosis, or a patient with 1 positive sputum $A F B$ smear and 1 positive sputum AFB culture. A patient with positive sputum smears for acid-fast bacilli after 5 or more months of treatment, or a patient who tested positive for the disease after testing negative, was defined as treatment failure (8).

\section{Study tool}

Factors that are known to affect tuberculosis treatment outcomes were identified from the literature and, based on these, a tool for data collection was designed for the study. Some of these factors were related to patients and their families, others were related to the health care system and personnel, and the remaining factors were social and environmental. These factors were then organized in the form of a checklist and a questionnaire consisting of 60 questions in 3 sections.

The first section recorded demographic factors, including age, sex, education, occupation, marital status, household size, lodging and ethnicity.

The second section collected data on clinical factors, including start date of treatment after diagnosis, number of smears, having a family history of tuberculosis, history of other diseases, use of other medications, use of tuberculosis drugs, medication complications, monitoring of the proper use of drugs (under DOTS) and the number of visits by the local physician to the patient's home in the initial and continuation phases.

The third section collected data on the social determinants of health and variables known to affect treatment outcome, including income, water consumption, alcohol use, tobacco 
use (cigarettes, waterpipe, pipe), narcotic drug use, nutrition (4 questions), proper training by health workers ( 8 questions) and patient knowledge ( 8 questions). A yes/no scale was utilized for each item on the multi-item scales, with a score of 1 assigned to a correct response and a score of 0 to an incorrect response. According to this grading scheme, the range of possible scores was 0-4 for patient's self-reported nutrition, 0-8 for correct training by health workers and 0-8 for patient's knowledge about tuberculosis.

The content validity of the questionnaire was confirmed by the scientific committee of Golestan University of Medical Sciences as well as by the health experts at the health care services department of Golestan province. A pilot study was carried out to assess the reliability of the questionnaire based on the results from a sample of 100 individuals meeting the requirements of the study. Cronbach alpha coefficient confirmed the reliability of the questions with Likert scales with a score of 0.87 , and the Kuder-Richardson coefficient confirmed the reliability of the yes/no questions with a score of 0.82 .

\section{Data collection}

After receiving a permit from the Golestan University of Medical Sciences, the names and addresses of the participants were extracted from the registry of tuberculosis patients in the tuberculosis units of the health centres of both cities. A checklist was first completed for each patient utilizing information obtained from the health records available at the health centres. Subsequently, we proceeded to the home of each patient and completed the questionnaire. Face-to-face interviews were carried out by a local health worker familiar with the patient being interviewed and his/her history. None of the selected patients refused to be interviewed.

Ethical considerations were observed in all phases of the study. The study protocol was approved by the ethics committee of Golestan University of Medical Sciences, and a permit was issued. Oral consent was obtained from all participants in the study. Furthermore, patients' names were not recorded on the interview sheets to ensure patients' privacy after data collection.

\section{Data analysis}

Descriptive and inferential (univariate and multivariate logistic regression) statistical analysis were performed using SPSS, version 18.0. Logistic regression analysis was used to calculate the risk of treatment failure. All variables were initially analysed utilizing univariate logistic regression. After that, all the significant predicators of treatment failure in the univariate regression were entered into the multivariate logistic regression model and were analysed by the backward conditional method. The significance level for all tests was 0.05 .

\section{Results}

\section{Background demographic and clinical characteristics}

Of the 167 patients analysed for the study $79(47.3 \%)$ were male and 88 (52.7\%) were female. The mean household size was 5.61 [standard deviation (SD) 2.40] with a range from 1 to 13 people. Almost all the patients (94.6\%) were of Iranian nationality and 5.4\% were of foreign origin; $55.1 \%$ of participants lived in a village and $44.9 \%$ in a city (Table 1).

The mean period between diagnosis and the start of treatment was 0.29 (SD 0.88 ) days, with a range from 0 to 7 days. All patients (100\%) claimed that they took their medications on time and that they received correct monitoring of proper use of drugs according to the DOTS system. The mean number of visits by the local physician in the initial phase of DOTS was 4.56 (SD 1.77) (range 0-10) and in the continuation phase was 3.79 (SD 2.11) (range 0-9).
The mean total scores for the questions about nutrition were 1.57 (SD 1.21) (range 1-4), for proper training by health workers were 6.85 (SD 1.40) (range 3-8) and for knowledge about TB were 5.35 (SD 2.20) (range 0-8).

\section{Factors associated with treatment failure}

Treatment results showed that 143 patients $(85.6 \%)$ were successfully treated and 24 (14.4\%) had treatment failure.

The results of univariate logistic regression analysis indicated that the following variables were significantly associated with treatment failure: male sex (OR 4.03; 95\% CI: 1.51-10.8, P = 0.005 ), Turkoman ethnicity (OR 5.61; 95\% CI: $1.34-23.6, P=0.018)$, household size (OR 0.81; 95\% CI: 0.68-0.97, $P=0.018)$, family history of tuberculosis (OR 0.22; 95\% CI: 0.49-0.97, P = 0.046 ), presence of other diseases (OR 5.73; 95\% CI: 2.27-14.5, $P<0.001)$, narcotic drug use (OR 2.48; $95 \% \mathrm{CI}$ : 1.01-6.11, $P=0.049$ ) and number of doctor visits in the continuation phase (OR 0.79; 95\% CI: 0.65-0.97, $P=0.024)$ (Table 2). Other variables, including responses to the questions about nutrition, training and knowledge about TB, were not significant in the univariate analysis.

After 4 phases of multivariate logistic regression analysis, being infected with other diseases (OR 9.35; 95\% CI: 3.01-29.1), male sex (OR 5.03; 95\% CI: 1.58-16.1), Turkoman ethnicity (OR 11.0; 95\% CI: 2.00-60.1), family history of tuberculosis (OR 0.21 ; 95\% CI: 0.05-0.96) and household size (OR 1.21; 95\% CI: 0.99-1.48) were found to be the strongest predictors of tuberculosis treatment failure. Narcotic drug use and the number of doctor visits in the continuation phase, though significant in the univariate analysis, were not significantly associated with treatment failure when analysed alongside other factors ( 0.05 error) using multivariate analysis (Table 2). 


\begin{tabular}{|c|c|c|c|c|c|c|}
\hline \multirow[t]{2}{*}{ Variable } & \multicolumn{2}{|c|}{$\begin{array}{l}\text { Success } \\
(n=143)\end{array}$} & \multicolumn{2}{|c|}{$\begin{array}{l}\text { Treatment failure } \\
\qquad(n=24)\end{array}$} & \multicolumn{2}{|c|}{$\begin{array}{c}\text { Total } \\
(n=167)\end{array}$} \\
\hline & No. & $\%$ & No. & $\%$ & No. & $\%$ \\
\hline \multicolumn{7}{|l|}{ Sex } \\
\hline Male & 61 & 42.7 & 18 & 75.0 & 79 & 47.3 \\
\hline Female & 82 & 57.3 & 6 & 25.0 & 88 & 52.7 \\
\hline \multicolumn{7}{|l|}{ Age (years) } \\
\hline$<15$ & $1 \mathrm{tt}$ & 0.7 & 0 & 0.0 & 1 & 0.6 \\
\hline $15-24$ & 19 & 13.3 & 0 & 0.0 & 19 & 11.4 \\
\hline $25-44$ & 52 & 36.4 & 5 & 20.8 & 57 & 34.1 \\
\hline $45-64$ & 36 & 25.2 & 11 & 45.8 & 47 & 28.1 \\
\hline$\geq 65$ & 35 & 24.5 & 8 & 33.3 & 43 & 25.7 \\
\hline \multicolumn{7}{|l|}{ Marital status } \\
\hline Single & 28 & 19.6 & 2 & 8.3 & 30 & 18.0 \\
\hline Married & 95 & 66.4 & 19 & 79.2 & 114 & 68.3 \\
\hline Widowed/divorced & 20 & 14.0 & 3 & 12.5 & 23 & 13.8 \\
\hline \multicolumn{7}{|l|}{ Ethnicity } \\
\hline Persian & 40 & 28.0 & 3 & 12.5 & 43 & 25.7 \\
\hline Turkoman & 19 & 13.3 & 8 & 33.3 & 27 & 16.2 \\
\hline Sistani/Baluchi & 75 & 52.4 & 12 & 50.0 & 87 & 52.1 \\
\hline Other & 9 & 6.3 & 1 & 4.2 & 10 & 6.0 \\
\hline \multicolumn{7}{|l|}{ Education } \\
\hline Illiterate & 72 & 50.3 & 15 & 62.5 & 87 & 52.1 \\
\hline Primary school and middle school & 45 & 31.5 & 7 & 29.2 & 52 & 31.1 \\
\hline High school/diploma & 17 & 11.9 & 2 & 8.3 & 19 & 11.4 \\
\hline University degree & 9 & 6.3 & 0 & 0.0 & 9 & 5.4 \\
\hline \multicolumn{7}{|l|}{ Occupation } \\
\hline Farmer & 9 & 6.3 & 3 & 12.5 & 12 & 7.2 \\
\hline Employee & 4 & 2.8 & 0 & 0.0 & 4 & 2.4 \\
\hline Labourer & 27 & 18.9 & 4 & 16.7 & 31 & 18.6 \\
\hline Businessperson & 18 & 12.6 & 5 & 20.8 & 23 & 13.8 \\
\hline Unemployed & 21 & 14.7 & 6 & 25.0 & 27 & 16.2 \\
\hline Housewife & 51 & 35.7 & 5 & 20.8 & 56 & 33.5 \\
\hline Student & 6 & 4.2 & 0 & 0.0 & 6 & 3.6 \\
\hline Other & 7 & 4.9 & 1 & 4.2 & 8 & 4.8 \\
\hline \multicolumn{7}{|l|}{ Household income } \\
\hline Low & 110 & 76.9 & 17 & 70.8 & 127 & 76.0 \\
\hline Medium & 30 & 21.0 & 5 & 20.8 & 35 & 21.0 \\
\hline High & 3 & 2.1 & 2 & 8.3 & 5 & 3.0 \\
\hline \multicolumn{7}{|l|}{ Family history of tuberculosis } \\
\hline Yes & 42 & 29.4 & 2 & 8.3 & 44 & 26.3 \\
\hline No & 101 & 70.6 & 22 & 91.7 & 123 & 73.7 \\
\hline \multicolumn{7}{|l|}{ Other diseases } \\
\hline Yes & 37 & 25.9 & 16 & 66.7 & 53 & 31.7 \\
\hline No & 106 & 74.1 & 8 & 33.3 & 114 & 68.3 \\
\hline \multicolumn{7}{|l|}{ Sufficient water consumption } \\
\hline Yes & 36 & 25.2 & 7 & 29.2 & 43 & 25.7 \\
\hline No & 107 & 74.8 & 17 & 70.8 & 124 & 74.3 \\
\hline
\end{tabular}




\begin{tabular}{|c|c|c|c|c|c|c|}
\hline \multirow[t]{2}{*}{ Variable } & \multicolumn{2}{|c|}{$\begin{array}{l}\text { Success } \\
(n=143)\end{array}$} & \multicolumn{2}{|c|}{$\begin{array}{l}\text { Treatment failure } \\
\qquad(n=24)\end{array}$} & \multicolumn{2}{|c|}{$\begin{array}{c}\text { Total } \\
(n=167)\end{array}$} \\
\hline & No. & $\%$ & No. & $\%$ & No. & $\%$ \\
\hline \multicolumn{7}{|l|}{ Alcohol use } \\
\hline Yes & 1 & 0.7 & 0 & 0.0 & 1 & 0.6 \\
\hline No & 142 & 99.3 & 24 & 100.0 & 166 & 99.4 \\
\hline \multicolumn{7}{|l|}{ Tobacco use } \\
\hline Yes & 19 & 13.3 & 3 & 12.5 & 22 & 13.2 \\
\hline No & 124 & 86.7 & 21 & 87.5 & 145 & 86.8 \\
\hline \multicolumn{7}{|l|}{ Narcotic drug use } \\
\hline Yes & 32 & 22.4 & 10 & 41.7 & 42 & 25.1 \\
\hline No & 111 & 77.6 & 14 & 58.3 & 125 & 74.9 \\
\hline \multicolumn{7}{|c|}{ No. of sputum smears } \\
\hline $3+$ & 54 & 37.8 & 13 & 54.2 & 67 & 40.1 \\
\hline $2+$ & 49 & 34.3 & 7 & 29.2 & 56 & 33.5 \\
\hline $1+$ & 21 & 14.7 & 3 & 12.5 & 24 & 14.4 \\
\hline 0 & 19 & 13.3 & 1 & 4.2 & 20 & 12.0 \\
\hline \multicolumn{7}{|c|}{ Medication complications } \\
\hline No side-effects & 139 & 97.2 & 24 & 100.0 & 163 & 97.6 \\
\hline Itching & 2 & 1.4 & 0 & 0.0 & 2 & 1.2 \\
\hline Jaundice & 1 & 0.7 & 0 & 0.0 & 1 & 0.6 \\
\hline Hearing loss & 1 & 0.7 & 0 & 0.0 & 1 & 0.6 \\
\hline Total & 143 & 100.0 & 24 & 100.0 & 167 & 100.0 \\
\hline
\end{tabular}

\section{Discussion}

This study showed that male sex, Turkoman ethnicity, having a family history of tuberculosis, the presence of other diseases and family size were the most important factors predicting failure of tuberculosis treatment under the DOTS schedule.

The finding that the male sex was an important predictor of tuberculosis treatment failure is consistent with other studies from different parts of the world. The generally accepted reason is that men are more active in society and the nature of some jobs (e.g. periods spent away from home) may be a risk factor for treatment failure (13-15).

In the analysis of ethnic groups and treatment failure, patients of Sistani and Baluchi ethnicity did not have the highest rate of treatment failure. This is surprising considering the fact that the Sistan-Baluchistan province was ranked number one in the incidence of the disease until 2008 (16) and that there has been a large migration of people from Sistan-Baluchistan province to Golestan province (17). However, the results of the present study showed that being of Turkoman ethnicity was a significant predictor for tuberculosis treatment failure. This might be explained by poverty, low education, large household size and/ or genetic factors. Given that no similar study with respect to the ethnicities of those infected in the area under study has been published, it is not possible to do a comparative analysis.

In the present study, household size was found to be one of the predictors of tuberculosis treatment failure, This result is in agreement with that of Alavi et al. elsewhere in the Islamic Republic of Iran (18) and Fisseha et al. in Ethiopia (19). Given that tuberculosis is associated with poverty, it seemed probable that an increase in the occurrence of treatment failure may be influenced by an increase in household size.

In this study, a history of tuberculosis in the family reduced the risk of treatment failure, as found too in Ethiopia (19). This may be due to a higher level of familiarity with the serious nature of this disease as well as with the steps involved in treating it. This extra level of familiarity meant those infected with tuberculosis from such families understood tuberculosis better, and put more effort towards their recovery. The results of this study are not in agreement, however, with a previous study in Golestan province by Adineh et al. (11).

Our study also revealed that the presence of other diseases in the patient during treatment was significantly associated with treatment failure. It seems likely that the co-morbidity burdens the immune system of the body. It is also possible that the presence of other 


\begin{tabular}{|c|c|c|c|c|}
\hline \multirow[t]{2}{*}{ Variable } & \multicolumn{2}{|c|}{ Univariate analysis } & \multicolumn{2}{|c|}{ Multivariate analysis } \\
\hline & OR & $95 \% \mathrm{CI}$ & OR & $95 \% \mathrm{CI}$ \\
\hline \multicolumn{5}{|l|}{ Sex } \\
\hline Male & 4.03 & $1.51-10.8$ & 5.03 & $1.58-16.1$ \\
\hline \multicolumn{5}{|l|}{ Ethnicity } \\
\hline Persian & - & & - & \\
\hline Turkoman & 5.61 & $1.34-23.6$ & 11.0 & $2.00-60.1$ \\
\hline Sistani/Baluchi & 3.79 & $0.41-35.1$ & 13.6 & 0.98-189 \\
\hline Other & 2.63 & $0.94-7.35$ & 2.90 & $0.65-12.8$ \\
\hline Household size & 0.81 & $0.68-0.97$ & 1.21 & $0.99-1.48$ \\
\hline \multicolumn{5}{|l|}{ Family history of tuberculosis } \\
\hline Yes & 0.22 & $0.49-0.97$ & 0.21 & $0.05-0.96$ \\
\hline \multicolumn{5}{|l|}{ Other diseases } \\
\hline Yes & 5.73 & $2.27-14.5$ & 9.35 & $3.01-29.1$ \\
\hline \multicolumn{5}{|l|}{ Narcotic drug use } \\
\hline Yes & 2.48 & $1.01-6.11$ & NS & - \\
\hline $\begin{array}{l}\text { No. of doctor visits in the continuation } \\
\text { phase }\end{array}$ & 0.79 & $0.65-0.97$ & NS & - \\
\hline
\end{tabular}

$O R=$ odds ratio $; C I=$ confidence interval; $N S=$ not significant .

medications in the patient's system may interfere with the tuberculosis drugs, thereby reducing their effectiveness. This finding is in agreement with the studies in Kenya by Muture et al. (14) and in Thailand by Anunnatsiri et al. (20).

In the present study, no statistically significant relationship was found between tobacco and alcohol use during treatment and the occurrence of treatment failure, as shown by other researchers $(10,14,15,21,22)$. This was most likely due to the low number of smokers in the study as a result of the correct educational guidelines they have been receiving from health care employees in the areas under study.

According to the results of the present study, no significant association was found between area of residence (urban/rural) and treatment result. This is consistent with the results of another study in Islamic Republic of Iran by Jamaati et al. (23) and Fisseha et al. in Ethiopia (19). The likely reason for this finding is the fact that the direct monitoring of medication use under DOTS in the Islamic Republic of Iran is done in an identical manner in both villages and cities.

The present study also did not find any significant association between educational level and treatment results, although we did not observe treatment failure in any of the individuals with a college education. This finding is in agreement with that of Demissie et al. in Ethiopia (24) and Chatterjee et al. in India (25). Our finding differs from another study in Tehran, Islamic Republic of Iran by Jamaati et al. (23) and the discrepancy is most likely due to the low educational level of most of the individuals in our study.

We also did not find any significant association between family income and treatment outcomes. This finding is consistent with the study by Jamaati et al. in the Islamic Republic of Iran (23), but is not consistent with the studies by Muture et al. in Kenya (14), Tachfouti et al. in Morocco (22) and Namukwaya et al. in Uganda (26) Despite the logical expectation that low income should be one of the important factors in treatment results, this was not confirmed by our study, most probably because anti-tuberculosis medication is provided free of charge in the Islamic Republic of Iran and therefore incurs no economic burden on family finances.

It might be expected that an increase in the number of sputum smears taken would be associated with an increase in the likelihood of treatment failure because having more sputum smears taken indicates a more severe state of the disease. However, no statistically significant relationship between these factors was observed in our study. This finding is not consistent with the findings of Dooley et al. in Morocco (13) or Namukwaya et al. in Uganda (26) or Waghmare et al. in India (27). The fact that this variable was not found to be statistically significant in our study was probably due to the small size of our sample and/or to the fact that we paid more attention to monitoring those with a higher number of positive smears.

The results of the study showed no statistically significant association between patient training/knowledge and treatment result. This finding is not consistent with the findings of Jamaati et al. (23). This inconsistency is most 
likely due to the fact that knowledge acquired through training about the disease is not sufficient to cause a change in behaviour; a change in attitude is also required.

We found a statistically significant association between narcotic drug use and treatment outcome in the univariate logistic regression analysis. This phenomenon may be caused by the interaction between anti-tuberculosis drugs and methadone and other chemicals present in narcotic drugs. However, when this variable was measured together with other variables in the multivariate logistic regression, narcotic drug use was no longer found to be a statistically significant factor in treatment outcome. The reason for this is not clear and will require further investigation. Our result, however, was not in agreement with another study in the Islamic Republic of Iran (10).

Similarly, the association between tuberculosis treatment outcome and the number of doctor visits in the continuation phase was statistically significant only in the univariate logistic regression and not in the multivariate logistic regression.
The limitations of the present study included illegible and incomplete case files, poor patient recall of events and the need to stimulate patients' memory though some strategically designed questions, the need for the presence of the researchers at the home of the patients, and the tendency of patients to resist providing correct answers to unfamiliar researchers.

\section{Conclusion}

This study showed that male sex, Turkoman ethnicity, having a family history of tuberculosis, the presence of other diseases and household size were the most important predictors for tuberculosis treatment failure under the DOTS strategy in this area of Golestan province.

Given that the presence of other diseases is one of the strongest risk factors associated with treatment failure in tuberculosis patients, it is recommended that the health care administrators in the Islamic Republic of Iran devise special programmes for this high-risk group. Of utmost importance is the need to follow up more frequently with the tuberculosis patients under DOTS to make sure they are following all the recommendations of their physicians.

It is also recommended that medical centres specializing in tuberculosis treatment be built in Golestan province in order to facilitate access, especially for Turkoman individuals who are disproportionately impacted by this disease. It is believed that, given the highly contagious and socially sensitive nature of this disease, most tuberculosis patients would feel more comfortable attending a hospital solely dedicated to infectious diseases.

\section{Acknowledgements}

We would like to thank the Administrators of the Golestan University of Medical Sciences, Dr Naser Behnampour, health professionals, workers and the tuberculosis unit physicians of the cities of Gorgan and Aqqala.

Funding: This study was funded by the Islamic Azad University of Tehran (Grant No. 1094111).

Competing interests: None declared.

\section{References}

1. Haghdoost AA. Different models of non-communicable and communicable diseases, from theory to practice. In: Proceedings of the Sixth National Epidemiology Conference, 13-15 July 2010, Shahrood, Islamic Republic of Iran. Journal of Knowledge and Health. 2010 Summer;5:192.

2. Raeesi A. Comprehensive guideline of communicable diseases surveillance system for family physicians. 1st ed. Tehran: Ministry of Health; 2013. p. 11.

3. Global tuberculosis report 2012. Geneva: World Health Organization; 2012 (http://apps.who.int/iris/bitstre am/10665/75938/1/9789241564502_eng.pdf, accessed 16 November 2015).

4. Incidence of tuberculosis in Iran [Internet]. Tehran: Ministry of Health and Medical Education; 2012 (http://www.cdc.hbi.ir/ Iran_global_tb_map.html, accessed 16 November 2015).

5. Tuberculosis: definitions [Internet]. Geneva: World Health Organization (http://www.who.int/tb/publications/2009/ airborne/background/definition/en/, accessed 16 November 2015).

6. Morsy AM, Zaher HH, Hassan MH, Shouman A. Predictors of treatment failure among tuberculosis patients under DOTS strategy in Egypt. East Mediterr Health J. 2003 Jul;9(4):689-701. PMID:15748066
7. Vasankari T, Holmström P, Ollgren J, Liippo K, Kokki M, Ruutu P. Risk factors for poor tuberculosis treatment outcome in Finland: a cohort study. BMC Public Health. 2007;7:291-9. PMID:17935630

8. Nasehi M, Mir Haghani L. National tuberculosis guide. 2nd ed. Tehran: Andishmand; 2009.

9. Tavanaei Sani A, Nouri M. Success with the DOTS strategy and estimated of MDR in Mashhad. Iran J Infect Dis Trop Med. 2006 Summer;33:21-5.

10. Adineh HA, Motametdi B, Veisi M, Bagheri S. Risk factors of tuberculosis treatment failure in south-east of Iran. Journal of Gorgan University of Medical Science. 2014 Summer;16(2):50-6.

11. Ghaemi E, Ghazisaidei K, Kohsarei H, Khodabakhshei B, Kohsar F, Behnampour N, et al. The comparison of environmental Mycobacteriums in the regions with high and low prevalence of tuberculosis in Golestan province. J Gorgan Uni Med Sci. 2002;4(2):48-53.

12. Statistical yearbook. Golestan, Islamic Republic of Iran: Golestan Province Health Centre; 2011:72-4 [in Persian].

13. Dooley KE, Lahlou O, Ghali I, Knudsen J, Elmessaoudi MD, Cherkaoui I, et al. Risk factors for tuberculosis treatment failure, default, or relapse and outcomes of retreatment in Morocco. BMC Public Health. 2011;11:140. PMID:21356062 
14. Muture BN, Keraka MN, Kimuu PK, Kabiru EW, Ombeka VO, Oguya F. Factors associated with default from treatment among tuberculosis patients in Nairobi province, Kenya: a case-control study. BMC Public Health. 2011;11:696. PMID:21906291

15. Santha T, Garg R, Frieden TR, Chandrasekaran V, Subraman R, Gopi PG, et al. Risk factors associated with default, failure and death among tuberculosis patients treated in a DOTS programme in Tiruvallur district, South India, 2000. Int J Tuberc Lung Dis. 2002 Sep;6(9):780-8. PMID:12234133

16. Meysamie A, Salehi M, Sargolzaei N. Trend of smear positive pulmonary tuberculosis in Sistan and Baluchestan Province (2005-2008). National Research Institute of Tuberculosis and Lung Disease, Iran. 2010;9(1):48-53.

17. Azizi MH, Bahadori M. A brief history of tuberculosis in Iran during the 19th and 20th centuries. Arch Iran Med. 2011 May;14(3):215-9. PMID:21529117

18. Alavi SM, Salmanzadeh S, Bakhtiyariniya P, Albagi A, Hemmatnia F, Alavi L. Prevalence and treatment outcome of pulmonary and extrapulmonary pediatric tuberculosis in southwestern Iran. Caspian J Intern Med. 2015 Fall;6(4):213-9

19. Fisseha G, Etana B, Haileslassie K, Alemayehu M. Determinant factors of treatment failure among tuberculosis patients under directly observed therapy in Tigray regional state public hospitals, north Ethiopia: a case-control study. Global Journal of Medical Research: F Diseases. 2104;14(5):version 1.0

20. Anunnatsiri S, Chetchotisakd P, Wanke C. Factors associated with treatment outcomes in pulmonary tuberculosis in northeastern Thailand. Southeast Asian J Trop Med Public Health. 2005 Mar;36(2):324-30. PMID:15916037
21. Albuquerque $M$, Alencar Ximenes RA, Lucena-Silva N, Souza WV, Dantas A, Dantas OMS, et al. Factors associated with treatment failure, dropout, and death in a cohort of tuberculosis patients in Recife, Pernambuco State, Brazil. Cad Saude Publica. 2007 Jul;23(7):1573-82.PMID:17572806

22. Tachfouti N, Nejjari C, Benjelloun MC, Berraho M, Elfakir S, E Rhazi K, et al. Association between smoking status, other factors and tuberculosis treatment failure in Morocco. Curr Opin Pulm Med. 2012;18(3):233-40. PMID:22388583

23. Jamaati HR, Mansoori SD, Zahedpour Anaraki MR, Mirsaeidi SM, Kazempour Dizaji M, Eskandari M. Contributing factors in anti-tuberculosis treatment failure. Tanaffos. 2003;2(7):61-8.

24. Demissie M, Kebede D. Defaulting from tuberculosis treatment at the Addis Abeba tuberculosis centre and factors associated with it. Ethiop Med J. 1994 Apr;32(2):97-106. PMID:8033883

25. Chatterjee P, Banerjee B, Dutt D, Pati RR, Mullick AK. A comparative evaluation of factors and reasons for defaulting in tuberculosis treatment in the states of West Bengal, Jharkhand and Arunachal Pradesh. Indian J Tuberc. 2003;50(1):17-22.

26. Namukwaya E, Nakwagala FN, Mulekya F, Mayanja-Kizza H, Mugerwa R. Predictors of treatment failure among pulmonary tuberculosis patients in Mulago hospital, Uganda. Afr Health Sci. 2011 Aug;11(1) Suppl 1:S105-11. PMID:22135634

27. Waghmare VN, Ingle VV, Totala PR. Factors associated with default from treatment among patients of pulmonary tuberculosis. International Medical Journal. 2015 Sept;2(9):565-56. 